\title{
APPLICATION OF EXPERIMENTAL DESIGN METHOD FOR THE OPTIMISATION OF XANTHAN GUM PRODUCTION FROM PINEAPPLE PEELS USING Xanthomonas Campestris via SUBMERGED FERMENTATION
}

\author{
N. A. Amenaghawon ${ }^{1, *}$, S. 0. Osemwengie ${ }^{2}, 0$. Omoregbe $^{3}$ and U. J. Asogwa ${ }^{4}$ \\ 1, 2, 3, 4 Department of Chemical Engineering, University of Benin, PMB 1154, Benin City, Edo State, NiGERIA. \\ E-mail addresses:1andrew.amenaghawon@uniben.edu, ${ }^{2}$ saint.osemwengie@uniben.edu, \\ 3 osaze.omoregbe@uniben.edu, ${ }^{4}$ uchenna.asogwa@eng.uniben.edu
}

\begin{abstract}
Xanthan gum is a major biopolymer which finds a lot of applications industrially and domestically. Biotechnological production of xanthan gum from waste biomass has been reported to be sustainable in terms of economics and viability. In this study, xanthan gum was produced from pineapple peels using Xanthomonas campestris by submerged fermentation. A three-variable, three-level Box-Behnken design (BBD) was used to develop a statistical model to study the effects of fermentation time, concentration of nitrogen $\left(\mathrm{NH}_{4} \mathrm{NO}_{3}\right)$ and phosphorus $\left(\mathrm{KH}_{2} \mathrm{PO}_{4}\right)$ on the amount of xanthan gum produced. Response surface methodology (RSM) was used to optimise these process variables. Results obtained showed that the model was statistically significant $(p<0.0001)$ and did not show lack of fit $\left(R^{2}=0.989\right)$. The results also showed that xanthan gum production was positively influenced by high levels of phosphorus and low levels of nitrogen. Increasing the fermentation time also favoured the production of xanthan gum. Results obtained from RSM revealed that the optimum fermentation time, nitrogen and phosphorus concentration were 3 days, $2 \mathrm{~g} / \mathrm{L}$ and $15 \mathrm{~g} / \mathrm{L}$ respectively. Under these conditions, the xanthan concentration was obtained as $8.48 \mathrm{~g} / \mathrm{L}$. Validation of the model indicated no significant difference between predicted and experimental values.
\end{abstract}

Keywords: optimisation, xanthan gum, pineapple waste, xanthomonas campestris, fermentation

\section{INTRODUCTION}

Nigeria is the eight largest producer of pineapple in the world, accounting for almost $7 \%$ of world output (15.8 million tonnes) of pineapple [1].The processing of pineapple into different fruit drinks and other products typically results in the generation of solid pineapple wastes particularly the peels which account for about $10 \%$ of the weight of the original fruit [2]. These wastes are typically disposed of improperly particularly in less developed countries thereby causing serious environmental pollution problems. Currently, these waste materials have little or no use and they are most often used for limited purposes such as animal feed [3]. Since the waste material is rich in carbohydrate and other nutrients, it can serve as ideal substrate for the production of value added products such as xanthan gum, citric acid and bioethanol [4,5].

Xanthan gum is an extra cellular polysaccharide which is produced by strains of Xanthomonas spp. such as
Xanthomonas phaseoli, Xanthomonas campestris and Xanthomonas malvacearum. Amongst these strains, xanthan gum produced by Xanthomonas campestris has the most desirable properties and for this reason has gained commercial significance [6]. The structure of xanthan gum is made up of repeating units of pentasaccharide containing two molecular units of glucose, mannose and one molecular unit of glucuronic acid [3]. As a result of its outstanding rheological properties, xanthan gum finds a lot of applications as thickening, stabilizing and suspending agent in many industries such as food, cosmetics, paint, pharmaceutical, oil recovery, agriculture etc [7]. In the food industry, xanthan gum is used to improve sense appealing properties such as texture, appearance and flavour release [8]. Xanthan gum finds uses in the agricultural industry for the production of fertilizers and pesticides while in the petroleum industry, it is

*Corresponding Author Tel: +234 8069275563 
used as well drilling mud and as mobility control agent during enhanced oil recovery [8].

Large scale production of xanthan gum has been by submerged fermentation with batch processes preferred to continuous processes [9]. Also, the production of xanthan gum has been reported to be influenced by fermentation conditions such as type of bacterial strain, composition of fermentation medium, substrate type and concentration, agitation rate, aeration, temperature, $\mathrm{pH}$ etc [10-14]. Amongst these conditions, the growth of the xanthan gum producing microorganism is strongly influenced by the medium composition such as nitrogen and phosphorus. Thus xanthan gum production by Xanthomonas campestris could be improved by optimising the medium composition [15].

Response surface methodology based on statistically designed experiments has been found to be very useful in optimising multivariable processes [16]. It is employed for multiple regression analysis of quantitative data obtained from statistically designed experiments [17]. Accordingly, the objective of this study was to optimise the nutrient medium for the production of xanthan gum from pineapple peels using Xanthomonas campestris in batch mode. A three variable Box-Behnken design for response surface methodology was used to study the simultaneous effect of three independent variables (fermentation time, nitrogen and phosphorus concentration) for optimum xanthan gum production.

\section{MATERIALS AND METHODS}

\subsection{Feedstock}

Pineapple peels, obtained from a local market in Benin City, Edo State, Nigeria were used as carbon substrate in this study. The physico-chemical composition of pineapple peels has been previously reported in a study by Huanget al. [18]. The peels were washed with clean water to remove any adhering dirt after which they were blended to obtain a slurry which was autoclaved at $121^{\circ} \mathrm{C}$ for 20 minutes. The $\mathrm{pH}$ of the slurry was adjusted to 7 prior to use as carbon substrate for xanthan gum production.

\subsection{Microorganism and inoculum preparation}

Xanthomonas campestris ATCC was obtained from the biotechnology Department of the Federal Institute of Industrial Research Oshodi (FIIRO), Lagos State, Nigeria. The stock culture was stored on agar slants and was maintained at $4{ }^{\circ} \mathrm{C}$ and the subcultures were revived every two weeks to avoid strain degradation [19].

\subsection{Fermentation}

Submerged fermentation was carried out in $250 \mathrm{~mL}$ Erlenmeyer flasks with a working volume of $100 \mathrm{~mL}$. The production medium had the following composition (g/L): carbon substrate (40), citric acid (2.1), $\mathrm{MgCl}_{2}$ (0.507), $\mathrm{Na}_{2} \mathrm{SO}_{4}$ (0.089), $\mathrm{H}_{3} \mathrm{BO}_{3}$ (0.06), $\mathrm{ZnO}(0.06)$, $\mathrm{FeCl}_{3} 6 \mathrm{H}_{2} \mathrm{O}(0.02), \mathrm{CaCO}_{3}(0.02)$ and $\mathrm{HCl}(0.013 \% \mathrm{v} / \mathrm{v})$. The $\mathrm{pH}$ was adjusted to 7 prior to beginning the fermentation run [20]. The flasks were placed in an orbiter shaker rotating at a rate of $120 \mathrm{rpm}$ and the temperature was maintained at $30{ }^{\circ} \mathrm{C}$ [7]. The salts, $\mathrm{NH}_{4} \mathrm{NO}_{3}$ and $\mathrm{KH}_{2} \mathrm{PO}_{4}$ served as the sources of nitrogen and phosphorus respectively. Their concentrations were varied according to the experimental design [21]. The content of the flask was inoculated with $5 \% \mathrm{v} / \mathrm{v}$ of the inoculum to begin fermentation.

\subsection{Design of Experiment}

A three variable Box-Behnken design for response surface methodology was used to develop a statistical model to describe the production of xanthan gum from pineapple peels. The range of the variables that were optimised is shown in Table 1.

Table 1: Experimental range and level of the independent variables

\begin{tabular}{|c|c|c|c|c|c|}
\hline \multirow{2}{*}{\multicolumn{2}{|c|}{ Variables }} & \multirow{2}{*}{ Symbol } & \multicolumn{3}{|c|}{ Coded } \\
\hline & & & - & 0 & +1 \\
\hline Time $(\mathrm{d}$ & & $\mathrm{X}_{1}$ & 1 & 2 & 3 \\
\hline $\mathrm{NH}_{4} \mathrm{NO}_{3}$ & concentration & $\mathrm{X}_{2}$ & 2 & 4 & 6 \\
\hline $\mathrm{KH}_{2} \mathrm{PO}_{4}$ & concentration & $\mathrm{X}_{3}$ & 0 & 7.5 & 15 \\
\hline
\end{tabular}

The Box-Behnken design is suitable for the exploration of quadratic response surfaces and this design can be used to develop a second degree polynomial model which can be utilised for optimisation purposes [22]. The number of experimental run for this design is obtained from Equation (1).

$$
N=k^{2}+k+c_{p}
$$

Where $k$ is the number of factors and $c_{p}$ is the number of replications at the center point. The experimental design was developed using Design Expert ${ }^{\circledR}$ 7.0.0 (Statease, Inc. Minneapolis, USA). The coded and actual values of the independent variables were calculated using Equation (2).

$$
X_{i}=\frac{X_{i}-X_{0}}{\Delta X_{i}}
$$


Where $x_{i}$ and $X_{i}$ are the coded and actual values of the independent variable respectively. $X_{O}$ is the actual value of the independent variable at the center point and $\Delta X_{i}$ is the step change of $X_{i}$. The following generalised second order polynomial equation was used to estimate the response of the dependent variable [16].

$$
Y_{i}=b_{o}+\sum b_{i} X_{j}+\sum b_{i j} X_{i} X_{j}+\sum b_{i i} X_{1}^{2}
$$

where $Y_{i}$ is the dependent variable or predicted response, $X$ and $X_{j}$ are the independent variables, $b_{o}$ is offset term, $b_{i}$ and $b_{i j}$ are the single and interaction effect coefficients and $e_{i}$ is the error term. The Design Expert software was used for regression and graphical analysis of the experimental data. The goodness of fit of the model for xanthan gum production was evaluated by the coefficient of determination $\left(\mathrm{R}^{2}\right)$ and analysis of variance (ANOVA). The optimum values of the variables tested were obtained by numerical optimisation based on the criterion of desirability [23].

\subsection{Xanthan Gum Recovery and Purification}

The microbial cells were removed from the viscous fermentation broth via centrifugation after diluting the broth. Xanthan gum was recovered from the broth via precipitation using two volumes of isopropyl alcohol (to one volume of xanthan sample) and $2 \% \mathrm{w} / \mathrm{w}$ potassium chloride. The samples were subjected to repeated precipitations (three times) for further purification after which the final precipitate was dried in an oven at $40^{\circ} \mathrm{C}$ for 24 hours [7].

\section{RESULTS AND DISCUSSION}

\subsection{Statistical analysis}

The Box-Behnken design resulted in 17 experimental runs as shown in Table 2. By applying multiple regression analysis to the experimental data, Equation (4) was obtained. This second degree polynomial equation was used to estimate the response, xanthan gum concentration.

$$
\begin{aligned}
Y=9.24+0.66 & X_{1}-1.82 X_{2}+0.060 X_{3} \\
& +0.20 X_{1} X_{2}+0.0033 X_{1} X_{3} \\
& +0.013 X_{2} X_{3}-0.073_{1}^{2}+0.11 X_{2}^{2} \\
& +0.0015 X_{3}^{2}
\end{aligned}
$$

The values of xanthan gum concentration as predicted by Equation (4) are given in Table 2 along with the experimental data. The significance of the fit of the xanthan gum model was assessed by carrying out analysis of variance (ANOVA).

\begin{tabular}{|c|c|c|c|c|c|c|c|c|}
\hline \multirow{3}{*}{ Run no } & \multicolumn{6}{|c|}{ Factors } & \multirow{2}{*}{\multicolumn{2}{|c|}{$\begin{array}{c}\text { Response } \\
\text { Xanthan concentration }(\mathrm{g} / \mathrm{L})\end{array}$}} \\
\hline & \multicolumn{3}{|c|}{ Coded values } & \multicolumn{3}{|c|}{ Actual values } & & \\
\hline & $X_{1}$ & $X_{2}$ & $x_{3}$ & $X_{1}$ & $X_{2}$ & $X_{3}$ & Observed & Predicted \\
\hline 1 & -1 & -1 & 0 & 1 & 2 & 7.5 & 7.22 & 7.15 \\
\hline 2 & +1 & -1 & 0 & 3 & 2 & 7.5 & 7.52 & 7.54 \\
\hline 3 & -1 & +1 & 0 & 1 & 6 & 7.5 & 4.58 & 4.56 \\
\hline 4 & +1 & +1 & 0 & 3 & 6 & 7.5 & 6.45 & 6.52 \\
\hline 5 & -1 & 0 & -1 & 1 & 4 & 0.0 & 4.47 & 4.51 \\
\hline 6 & +1 & 0 & -1 & 3 & 4 & 0.0 & 5.67 & 5.63 \\
\hline 7 & -1 & 0 & +1 & 1 & 4 & 15.0 & 6.46 & 6.50 \\
\hline 8 & 0 & 0 & +1 & 3 & 4 & 15.0 & 7.76 & 7.72 \\
\hline 9 & 0 & 0 & -1 & 2 & 2 & 0.0 & 6.65 & 6.67 \\
\hline 10 & 0 & +1 & -1 & 2 & 6 & 0.0 & 4.52 & 4.49 \\
\hline 11 & 0 & -1 & +1 & 2 & 2 & 15.0 & 8.31 & 8.34 \\
\hline 12 & 0 & +1 & +1 & 2 & 6 & 15.0 & 6.93 & 6.91 \\
\hline 13 & 0 & 0 & 0 & 2 & 4 & 7.5 & 5.81 & 6.08 \\
\hline 14 & 0 & 0 & 0 & 2 & 4 & 7.5 & 6.21 & 6.08 \\
\hline 15 & 0 & 0 & 0 & 2 & 4 & 7.5 & 6.28 & 6.08 \\
\hline 16 & 0 & 0 & 0 & 2 & 4 & 7.5 & 6.22 & 6.08 \\
\hline 17 & 0 & 0 & 0 & 2 & 4 & 7.5 & 5.86 & 6.08 \\
\hline
\end{tabular}

ANOVA results showed that the model was statistically significant with a very low $p$ value $(p<0.0001)$ as shown in Table 3. The model did not show lack of fit as seen from the "lack of fit" p value of 0.9401 .

Table 2: Box-Behnken design matrix for xanthan gum production 
The first order main effects of fermentation time, nitrogen concentration and phosphorus concentration were significant as evident from their respective $\mathrm{p}$ values. This suggests that $\mathrm{NH}_{4} \mathrm{NO}_{3}$ and $\mathrm{KH}_{2} \mathrm{PO}_{4}$ could act as limiting nutrients such that minute changes in their concentration could affect the growth rate of cells as well as product formation rate [4]. The parity plot comparing experimental values of the response and those predicted by the statistical model showed that there was an acceptable level of correlation between the experimental and model predicted results as shown in Figure 1. This is evident from the fact that the data points all clustered around the $45^{\circ}$ diagonal line showing that there was minimal deviation between experimental and predicted values thus indicating optimal fit of the model.

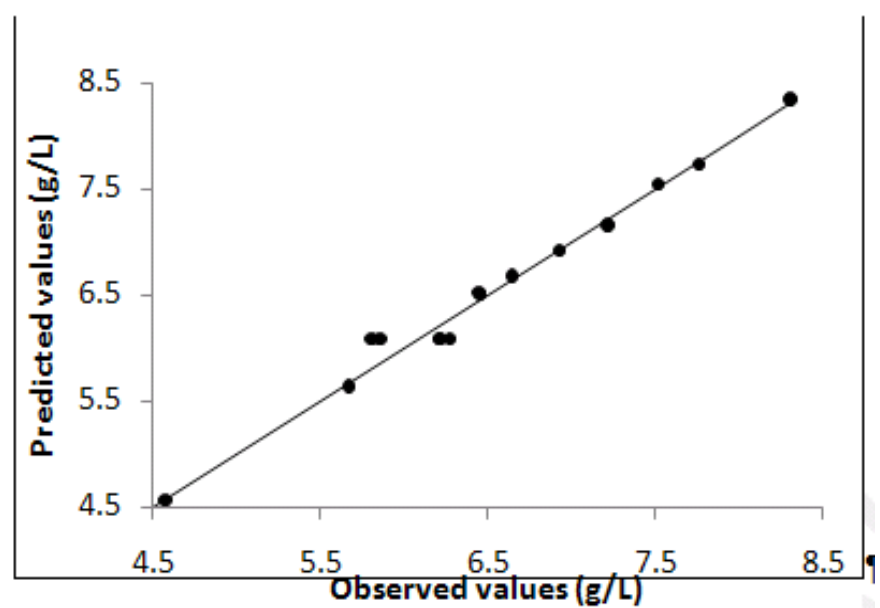

Figure 1: Parity plot showing comparison between experimental and predicted values
Statistical information for ANOVA shows that the model had a high coefficient of determination $\left(\mathrm{R}^{2}\right)$ as shown in Table 4. This shows that the model was able to adequately represent the relationship between the chosen factors (fermentation time, nitrogen concentration and phosphorus concentration) and the response (xanthan gum concentration). An $\mathrm{R}^{2}$ value of 0.989 means that the model was able to explain $98.9 \%$ of the variability observed in the values of xanthan gum concentration. The standard deviation was observed to be relatively small compared to the mean. The coefficient of variation (CV) was obtained as 2.80 . This value gives an indication of the degree of precision with which the treatments were carried out [24]. The relatively low value of $\mathrm{CV}$ obtained showed that the treatments were carried out with high precision and reliability [25]. The Adequate precision for the model was obtained as 28.50 showing that the model can be used to navigate the design space.

\section{Table 4: Statistical information for ANOVA of}

\begin{tabular}{ll}
\hline Parameter & Response \\
\hline R-Squared & 0.989 \\
Adjusted R-Squared & 0.975 \\
Mean & 6.29 \\
Standard Deviation & 0.18 \\
C.V \% & 2.80 \\
Adeq. Precision & 28.50 \\
\hline
\end{tabular}

Table 3: ANOVA results for xanthan gum production model

\begin{tabular}{lccccl}
\hline Source & Sum of Squares & df & Mean Square & F value & $\mathrm{p}$ value \\
\hline Model & 19.18 & 9 & 2.13 & 68.94 & $<0.0001$ \\
$X_{1}$ & 2.73 & 1 & 2.73 & 88.21 & $<0.0001$ \\
$X_{2}$ & 6.52 & 1 & 6.52 & 210.83 & $<0.0001$ \\
$X_{3}$ & 8.30 & 1 & 8.30 & 268.64 & $<0.0001$ \\
$X_{1} X_{2}$ & 0.62 & 1 & 0.62 & 19.94 & 0.0029 \\
$X_{1} X_{3}$ & $2.5 \mathrm{E}-3$ & 1 & $2.5 \mathrm{E}-3$ & 0.081 & 0.7843 \\
$X_{2} X_{3}$ & 0.14 & 1 & 0.14 & 4.55 & 0.0703 \\
$X_{1}{ }^{2}$ & 0.022 & 1 & 0.022 & 0.73 & 0.4224 \\
$X_{2}{ }^{2}$ & 0.81 & 1 & 0.81 & 26.32 & 0.0014 \\
$X_{3}{ }^{2}$ & 0.032 & 1 & 0.032 & 1.03 & 0.3437 \\
\hline Residual & 0.22 & 7 & 0.031 & & \\
Lack of Fit & 0.019 & 3 & $6.21 \mathrm{E}-3$ & 0.13 & 0.9401 \\
Pure Error & 0.20 & 4 & 0.049 & & \\
Cor Total & 19.39 & 16 & & & \\
\hline
\end{tabular}



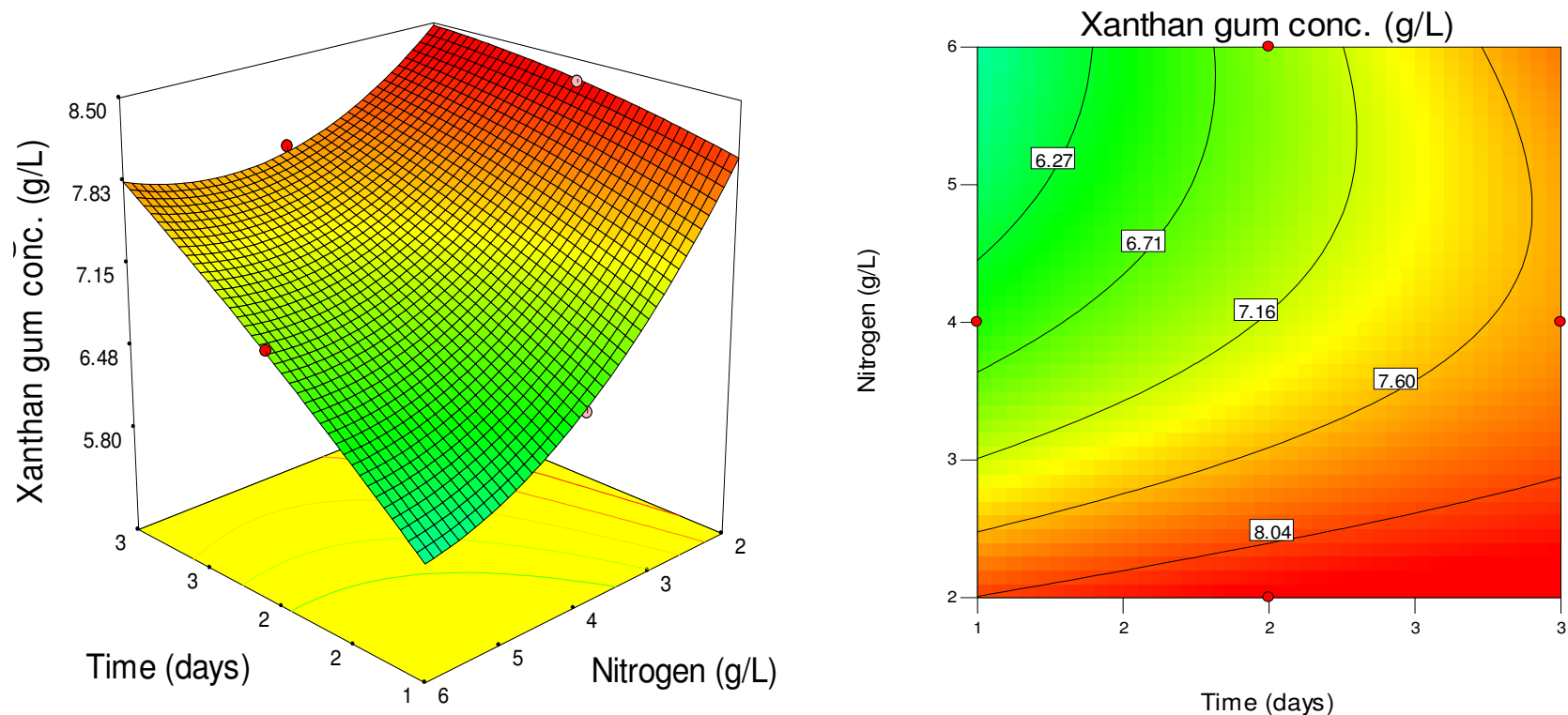

Figure 2: Response surface plot and the corresponding contour plot showing the effects of time and nitrogen on xanthan gum concentration
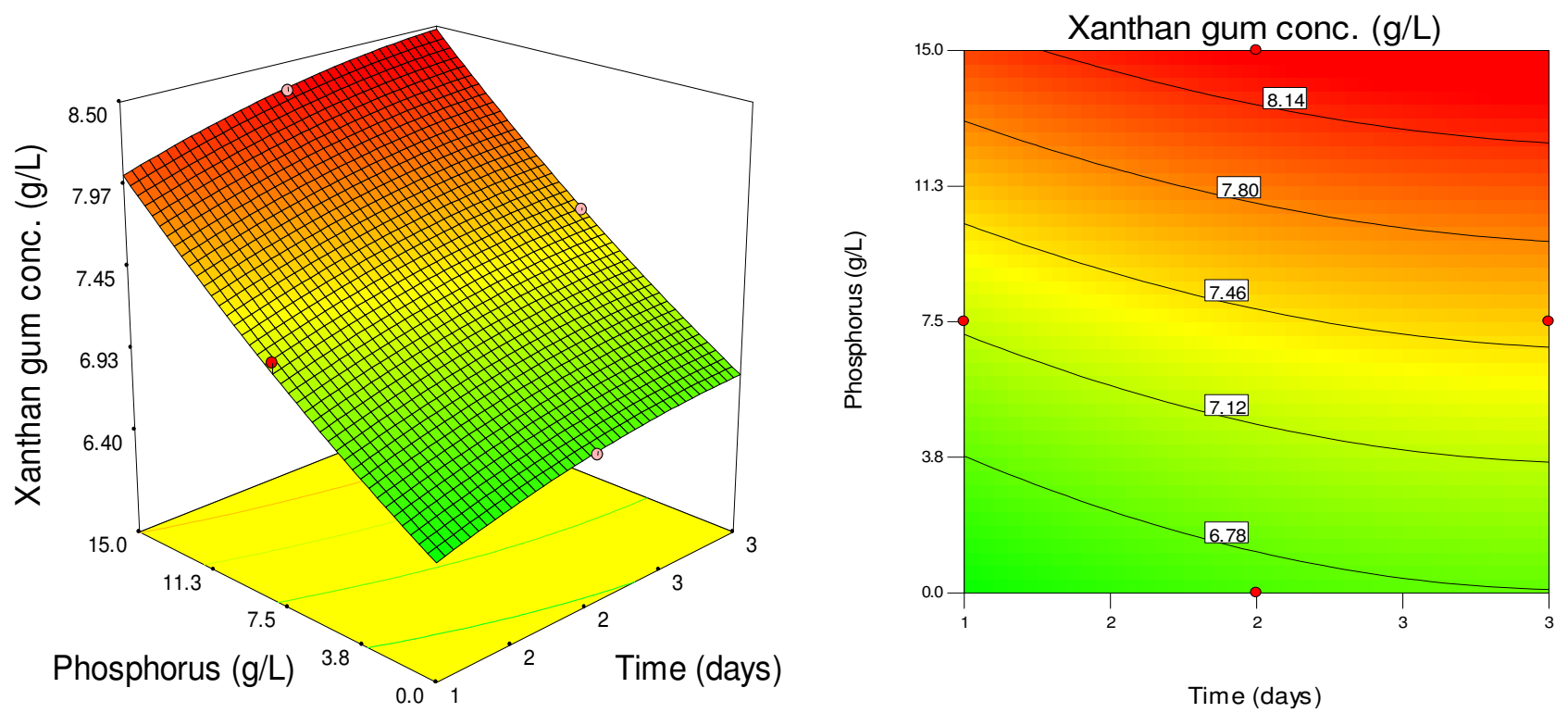

Figure 3: Response surface plot and the corresponding contour plot showing the effects of phosphorus and time on xanthan gum concentration

\subsection{Optimisation of xanthan gum production}

In order to optimise the variables that influence xanthan gum production, response surface plots were generated from the statistical model. The three dimensional (3D) plots were generated by keeping one variable constant at the center point and varying the others within the experimental range. The resulting response surfaces showed the effect of fermentation time, nitrogen and phosphorus concentration on xanthan gum production. Figure 2 shows the concentration of xanthan gum at different concentrations of nitrogen and fermentation days with the concentration of phosphorus kept constant. Higher xanthan gum concentrations were obtained when the fermentation time was increased. This suggests the progressive conversion of the carbon substrate to xanthan gum in the course of the fermentation process. Maximum xanthan production was recorded at a fermentation time of 3 days. The fermentation time is an important factor that should be optimised during xanthan gum production due to the possibility of reducing the cost of production as a result of time savings. Cacik et al. [26] developed an optimal control procedure to reduce the fermentation time necessary to produce a desired amount of xanthan gum. 

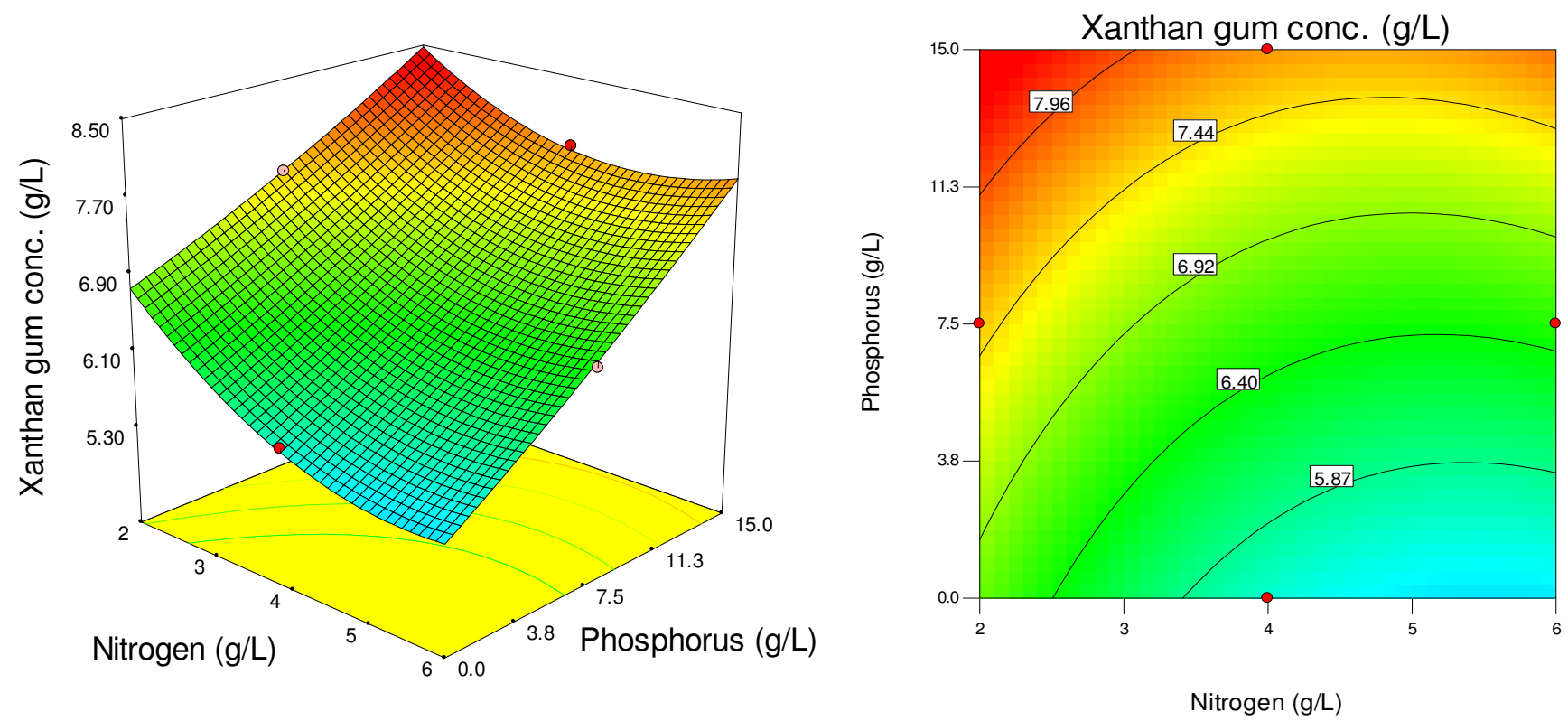

Figure 4: Response surface plot and the corresponding contour plot showing the effects of nitrogen and phosphorus on xanthan gum concentration

Their results showed that by adopting the minimum time optimal procedure, the fermentation time needed to produce $15 \mathrm{~g} / \mathrm{L}$ of gum could be reduced by as much as $16.3 \%$ when the usual constant temperature of $28^{\circ} \mathrm{C}$ is used and $12 \%$ when the two temperatures strategy of other authors is used with all the other culture conditions kept constant. Low levels of nitrogen concentration favoured xanthan gum production. This trend can be explained by the fact that during microbial fermentation, the nitrogen source is just needed for the preparation of growth conditions, cell maintenance and production of enzymes for the biocatalytic synthesis of xanthan gum. As is common with the synthesis of other bacterial exopolysaccharides, xanthan gum production is greater in media containing higher ratios of carbon to nitrogen $(\mathrm{C} / \mathrm{N})$ [21]. Owing to the fact that in this study the concentration of carbon substrate in the fermentation medium was constant, increasing the concentration of nitrogen resulted in a decrease in the $\mathrm{C} / \mathrm{N}$ ratio and this consequently resulted in a decline in xanthan production. Previous reports have also shown that low concentrations of nitrogen favoured xanthan gum production $[6,15,27]$ Phosphorus concentration had a positive influence on xanthan gum production as the concentration of xanthan gum was observed to increase with increase in phosphorus concentration as shown in Figures 3 and 4. The estimated coefficients of the model terms obtained from ANOVA showed that the effect of phosphorus concentration was more positively significant than that of fermentation time. Previous researchers have reported that phosphorus has a positive effect on xanthan gum production. Garcia-Ochoa and Casas [28] investigated the nutritional composition of the growth and fermentation media for xanthan gum production. Their results showed that nitrogen, phosphorous and magnesium influenced growth whereas nitrogen, phosphorous and sulfur influenced the production of xanthan.

Results presented in Figure 4 corroborated that presented in Figure 2 in that a low concentration of nitrogen was favourable for xanthan production. These results are in agreement with those reported by Souw and Demain [29] who showed that when nutrients like phosphorus and nitrogen are limiting, xanthan gum production could be enhanced.

The optimisation of the statistical model resulted in the selection of the optimum fermentation conditions and their respective levels. The maximum xanthan concentration predicted by the model was $8.48 \mathrm{~g} / \mathrm{L}$. The final optimised conditions for the production of xanthan gum as obtained from RSM were a fermentation time of 3 days, a nitrogen concentration of $3 \mathrm{~g} / \mathrm{L}$ and a phosphorus concentration of $15 \mathrm{~g} / \mathrm{L}$. This result is superior to earlier findings by other researchers. Gomashe et al. [30] studied the production of xanthan gum from sugar beet molasses and reported a maximum xanthan concentration of $3.59 \mathrm{~g} / \mathrm{L}$ after 5 days of fermentation. In another study, Palaniraj et al. [31] investigated the effect of nitrogen sources on 
xanthan gum production. The results of their study revealed that when yeast extract was used as the primary nitrogen source, the maximum production of xanthan was $3.6 \mathrm{~g} / \mathrm{L}$ in batch fermentation and $5.2 \mathrm{~g} / \mathrm{L}$ in fed batch fermentation. However, Murugesan et al. [32] and Farhadi et al. [33] reported maximum xanthan concentration of $12.23 \mathrm{~g} / \mathrm{L}$ and $14.61 \mathrm{~g} / \mathrm{L}$ respectively from the fermentation of sugar cane molasses and date extract respectively. The difference in the optimum concentration of xanthan obtained in these studies could be as a result of the difference in the type and level of sugar substrate used as well as the fermentation conditions.The statistical model was validated by comparing model predicted results with those of repeated experiments carried out at the optimised conditions. The mean of the results obtained from three replications was close to that predicted by the model thus showing validity.

\section{CONCLUSION}

The production of xanthan gum from pineapple peels via submerged batch fermentation was investigated in this study. A three-variable, three-level Box-Behnken design was used to study the simultaneous effect of fermentation time and the concentrations of nitrogen and phosphorus. The fermentation conditions were optimised using RSM. The statistical model developed to represent the fermentation process was statistically significant $(\mathrm{p}<0.0001)$ and showed a good fit with the experimental data $\left(\mathrm{R}^{2}=0.989\right)$. Low levels of nitrogen were favourable for xanthan gum production. Xanthan gum production was positively influenced by the fermentation time and phosphorus concentration as the concentration of xanthan gum was observed to increase when these variables were increased. The optimum nitrogen concentration, phosphorus concentration and fermentation time were $2 \mathrm{~g} / \mathrm{L}, 15$ $\mathrm{g} / \mathrm{L}$ and 3 days respectively. Under these conditions, the xanthan concentration was obtained as $8.48 \mathrm{~g} / \mathrm{L}$. The results obtained in this study could be utilised for the design of fermenters for increased xanthan gum production.

\section{REFERENCES}

[1] FAO (2010). Pineapple statistics. Food and Agriculture Organisation, Rome, Italy, p.28.

[2] Amenaghawon, N.A., Oronsaye, J.E and Ogbeide, S.E. "Statistical Optimisation of Fermentation Conditions for Citric Acid Production from Pineapple Peels", Nigerian Journal of Technological Research, Vol. 9, Number 2, 2014a, pp. 20-26.
[3] Salah, R.B., Chaari, K., Besbes, S., Ktari, N., Blecker, C., Deroanne, C. and Attia, H. "Optimisation of xanthan gum production by palm date (Phoenix dactylifera L.) juice by-products using response surface methodology. Food Chemistry, Vol. 121, 2010, pp. 627633.

[4] Imandi, S.B., Bandaru, V.V.R., Somalanka, S.R., Bandaru, S.R. and Garapati, H.R. "Application of statistical experimental designs for the optimization of medium constituents for the production of citric acid from pineapple waste", Bioresource Technology, Vol. 99, Number 10, 2008, pp. 4445-4450.

[5]. Kareem, S.O., Akpan, I. and Alebiowu, 0.0. "Production of citric acid by Aspergillus niger using pineapple waste", Malaysian Journal of Microbiology, Vol. 6, Number 2, 2010, pp. 161-165.

[6] El Enshasy, H., Then, C., Othman, N.Z., Al Homosany, H., Sabry, M., Sarmidi, M.R. and Aziz, R.A. "Enhanced xanthan production process in shake flasks and pilot scale bioreactors using industrial semidefined medium", African Journal of Biotechnology, Vol. 10, Number 6, 2011, pp. 1029-1038.

[7] Psomas, S.K., Liakopoulou-Kyriakides, M. and Kyriakidis, D.A. "Optimization study of xanthan gum production using response surface methodology", Biochemical Engineering Journal, Vol. 35, 2007, pp. 273-280.

8. Sutherland, I. "A Sticky Business. Microbial Polysaccharides: Current Products and Future Trends", Microbiology Today, Vol. 29, 2002, pp. 70-71.

[9] Kumara, S.M, Khan, B.A, Rohit, K.C, Purushotham, B. "Effect of carbon and nitrogen sources on the production of xanthan gum from Xanthomonas campestris isolated from soil", Archives of Applied Science Research, Vol. 4, Number 6 2012, pp. 25072512.

[10] Borges, C.D., Moreira, A.D.S., Vendruscolo, C. Ayub M.A.Z. "Influence of agitation and aeration in xanthan production by Xanthomonas campestris pv pruni strain 101", Revista Argentina de Microbiologia, Vol. 40, 2008, pp. 81-85.

[11] Borges, C.D., Paula, R.C.M., Feitosa, J.P.A., Vendruscolo, C.T. "The influence of thermal treatment and operational conditions on xanthan produced by $X$. arboricola pv pruni strain 106", Carbohydrate Polymers, Vol. 75, 2009, pp. 262-268.

[12] Chaitali, M., Kapadi, M., Suraishkumar, G.K. and Gudi, R.D. "Productivity improvement in xanthan gum fermentation using multiple substrate optimization", Biotechnology Progress, Vol. 19, Number 4, 2003, pp. 1190-1198.

[13] López, M.J., Vargas-Garcıa, M. C., Suarez-Estrella, F. and Moreno, J. "Properties of xanthan obtained from agricultural wastes acid hydrolysates", Journal of Food Engineering, Vol. 63, Number 1, 2004, pp. 111-115. 
[14] Moreira, A.S., Vendruscolo, J.L.S., Gil-Turnes, C. and Vendruscolo, C. T. "Screening among 18 novel strains of Xanthomonas campestris pv pruni:, Food Hydrocolloids, Vol. 15, Number 4, 2001, pp. 469-474.

[15] Garcia-Ochoa, F., Santos, V.E., Casas, J.A. and Gomez, E. "Xanthan Gum: Production, Recovery, and Properties", Biotechnology Advances, Vol. 18, 2000, pp. 549-579.

[16] Amenaghawon, N.A., Ogbeide, S.E. and Okieimen, C.O. "Application of Statistical Experimental Design for the Optimisation of Dilute Sulphuric Acid Hydrolysis of Cassava Bagasse", Acta Polytechnica Hungarica, Vol. 11, Number 9, 2014b, pp. 239-250

[17] Montgomery, D.C. Design and Analysis of Experiments, 6. ed., John Wiley \& Sons, Inc., New York, 2005.

[18] Huang, Y.L., Chow, C.J. and Fang, Y.J. "Preparation and physicochemical properties of fiber-rich fraction from pineapple peels as a potential ingredient", Journal of Food and Drug Analysis, Vol. 19, Number 3, 2011, pp. 318-323.

[19] Nasr, S., Soudi, M.R. and Haghighi, M. "Xanthan production by a native strain of $\mathrm{X}$. campestris and evaluation of application in EOR", Pakistan journal of biological sciences: PJBS, Vol. 10, Number 17, 2007, pp. 3010-3013.

[20] Casas, J.A., Santos, F. and Garcia-Ochoa, F. "Xanthan gum production under several operational conditions: molecular structure and rheological properties", Enzyme and Microbial Technology, Vol. 26, 2000, pp. 282-291.

[21] Moshaf, S., Hamidi, E.Z. and Azizi, M. H. "Optimization of Conditions for Xanthan Gum Production from Waste Date in Submerged Fermentation", World Academy of Science, Engineering, Vol. 5, 2011, pp. 9-23

[22] Amenaghawon, N.A, Nwaru, K.I., Aisien, F.A., Ogbeide, S.E and Okieimen, C.O."Application of Box-Behnken Design for the Optimization of Citric Acid Production from Corn Starch Using Aspergillus niger",British Biotechnology Journal, Vol. 3, Number 3, 2013b, pp. 236-245.

[23] Jargalsaikhan, O. and Saracoğlu, N. "Application of experimental design method for ethanol production by fermentation of sunflower seed hull hydrolysate using Pichia stipitis NRRL-124", Chemical Engineering Communications, Vol. 196, Number (1-2), 2008, pp. 93-103.
[24] Qi, B., Chen, X., Shen, F. and Wan, Y." Optimization of Enzymatic Hydrolysis of Wheat Straw Pretreated by Alkaline Peroxide Using Response Surface Methodology", Industrial and Engineering Chemistry Research, Vol. 48, 2009, pp. 7346-7353.

[25] Hou, X.J. and Chen, W. "Optimization of extraction process of crude polysaccharides from wild edible Bachu mushroom by response surface methodology", Carbohydrate Polymers, Vol. 72, 2008, pp. 67-74

[26] Cacik, F., Dondo, R.G. and Marqués, D. “Optimal control of a batch bioreactor for the production of xanthan gum", Computers \& Chemical Engineering, Vol. 25, Number 2, 2001, pp. 409-418.

[27] Lo, Y.M., Yang, S.T. and Min, D.B. "Effects of yeast extract and glucose on xanthan production and cell growth in batch culture of Xanthomonas campestris", Applied Microbiology and Biotechnology, Vol. 47, Number 6, 1997, pp. 689-694.

[28] Garcia-Ochoa, F. and Casas, J.A. "Viscosity of locust bean (Ceratonia siliqua) gum solutions", Journal of Science, Food and Agriculture, Vol. 59, 1992, pp. 97100.

[29] Souw, P. and Demain A.L. "Nutritional studies on xanthan production by Xanthomonas campestris NRRL B-1459", Applied and Environmental Microbiology, Vol. 37, 1979, pp. 1186-92.

[30] Gomashe, A.V., Dharmik, P.G. and Fuke, P.S. "Optimization and Production of Xanthan Gum by Xanthomonas Campestris NRRL-B-1449 from Sugar Beet Molasses", The International Journal of Engineering and Science, Vol. 2, Number 5, 2013, pp. 52-55.

[31] Palaniraj, A., Jayaraman, V. and Hariram, S.B. "Influence of nitrogen sources and agitation in xanthan gum production by Xanthomonas campestris", International Journal of Advanced Biotechnology and Research, Vol. 2, Number 3, 2011, pp. 305-309.

[32] Murugesan A.G., Dhevahi B., Gowdhaman D., Bala Amutha K. and Sathesh Prabu C. "Production of Xanthan employing Xanthomonas campestris using Sugarcane Molasses", American Journal of Environmental Engineering, Vol. 2, Number 2, 2012, pp. 31-34.

[33] Farhadi, G. B., Khosravi-Darani, K. and Nasernejad, B. "Enhancement of Xanthan Production on Date Extract Using Response Surface Methodology", Asian Journal of Chemistry, Vol. 24, Number 9, 2012, pp. 3887-3890. 